\title{
Mortality in Patients on Renal Replacement Therapy and Permanent Cardiac Pacemakers
}

\author{
Gabriel Vanerio, ${ }^{1,2}$ Cristina García, ${ }^{1}$ Carlota González, ${ }^{1,3}$ and Alejandro Ferreiro ${ }^{1,3,4}$ \\ ${ }^{1}$ CASMU Arrhythmia Service, 8 de Octubre 3310, 11600 Montevideo, Uruguay \\ ${ }^{2}$ British Hospital, Avenida Italia 2420, 11600 Montevideo, Uruguay \\ ${ }^{3}$ Uruguayan Registry of Dialysis, Uruguay \\ ${ }^{4}$ Nephrology Clinic, Hospital de Clinicas, Faculty of Medicine, The University of the Republic, Avenida Italia $s / n$, \\ 11600 Montevideo, Uruguay
}

Correspondence should be addressed to Gabriel Vanerio; gabvaner@gmail.com

Received 28 January 2014; Revised 6 April 2014; Accepted 7 April 2014; Published 26 May 2014

Academic Editor: David B. Kershaw

Copyright (C) 2014 Gabriel Vanerio et al. This is an open access article distributed under the Creative Commons Attribution License, which permits unrestricted use, distribution, and reproduction in any medium, provided the original work is properly cited.

\begin{abstract}
End stage renal disease is a relatively frequent disease with high mortality due to cardiac causes. Permanent pacemaker (PM) implantation rates are also very common; thus combination of both conditions is not unusual. We hypothesized that patients with chronic kidney disease with a PM would have significantly higher mortality rates compared with end stage renal disease patients without PM. Our objectives were to analyze mortality of patients on renal replacement therapy with PM. 2778 patients were on renal replacement therapy (RRT) and 110 had a PM implanted during the study period. To reduce the confounding effects of covariates, a propensity-matched score was performed. 52 PM patients and 208 non-PM matched patients were compared. $41 \%$ of the PM were implanted before entering the RRT program and 59\% while on RRT. Mortality was higher in the PM group. Cardiovascular disease and infections were the most frequent causes of death. Propensity analysis showed no differences in long-term mortality between groups. We concluded that in patients on RRT and PM mortality rates are higher. Survival curves did not differ from a RRT propensity-matched group. We concluded that the presence of a PM is not an independent mortality risk factor in RRT patients.
\end{abstract}

\section{Background}

Permanent cardiac pacing $(\mathrm{PM})$ is the treatment of choice in severe and symptomatic bradycardia. Several independent factors such as age, gender, comorbidities, presence of structural heart disease, stimulation modalities, index arrhythmia, and initial symptoms are associated with mortality [1-4].

End-stage renal disease is a relatively common condition associated with high mortality due to cardiovascular causes. Most deaths in patients on renal replacement therapy (RRT) are attributed to sudden cardiac death, which accounts for approximately one-quarter of all deaths [5-9]. Therefore, as chronic kidney disease is an increasingly prevalent condition and an independent risk factor for cardiovascular mortality, the presence of a permanent pacemaker is likely to increase mortality.

To our knowledge, no data is available regarding mortality in patients on RRT with permanent pacemakers (PM) [1012]. These groups of patients are not included in the current guidelines $[13,14]$. Mortality rates are likely to be higher due to the advanced age, the high incidence of stroke, and comorbidities. Estimation of outcomes after PM placement in long-term dialysis patients is needed to evaluate the risks and benefits of permanent cardiac stimulation $[5,6,15-21]$.

Our objectives were

(1) to analyze mortality in RRT patients with and without a PM;

(2) to compare survival and describe baseline characteristics of patients with PM on a RRT program.

\section{Methods}

We performed a longitudinal retrospective study from January 2003 to December 2008. Data was obtained from the Uruguayan National Resource Fund (FNR) database (which includes 99\% of PM implants and all dialysis units in Uruguay) [22]. The FNR is a nongovernmental public 
organization that provides financial coverage of medical procedures for the entire Uruguayan population. The FNR ensures financing and evaluates the quality of care provided to patients, controlling the processes and outcomes of the funded procedures.

Demographic data, comorbidities, time on RRT, clinical conditions, and the functional status evaluated by Karnofsky modified score (4 categories) were registered to perform comparisons between groups [23]. Data on comorbid conditions at the beginning of the study and the evolution were prospectively recorded using a standardized data collection tool (Basic Data and Evolution Questionnaire). We restricted the analysis to the first device implanted. Participants were followed up from PM implant date until March 30, 2010, or death.

2.1. Baseline Covariates. For each patient, we obtained demographic data and cause of renal failure from the FNR database. Variables included risk factors for mortality, such as history of myocardial infarction, coronary heart disease, ischemic stroke or transient ischemic attack, congestive heart failure, cardiac arrest, atrial fibrillation, chronic obstructive lung disease, cancer, and diabetes.

2.2. Outcomes. Outcomes of interest were all-cause mortality. Mortality date and cause of death were extracted from the FNR database.

2.3. Statistical Analysis. Categorical and continuous data are presented as absolute numbers and percentages or mean values and standard deviations, respectively. Variables were compared by the $\chi^{2}$ test, Fisher's exact test or Student's $t$-test, Wilcoxon test, and binary logistic regression when appropriate. Survival curves were constructed by the KaplanMeier method. Pooled-over strata log rank test or Breslow test was used for comparing the equality of survival distributions for the different levels of the factors. The log-rank test was used to compare curves. Due to the important imbalance of mortality-associated comorbidities between groups, patients who received a PM device while on RRT were propensitymatched accordingly with a logistic regression derived probability of death, adjusted to the confounding effects of covariates (age, sex, comorbidities, Karnofsky-based functional status, and previous time on dialysis). All variables significant at the $P<0.2$ level were entered into the multivariate model (forward stepwise binary logistic regression analysis) provided they were present in at least $2 \%$ of the sample. Variables were entered into the model separately, beginning with the variable having the highest statistically significant score. Variables that significantly improved the fit of the model were retained and forced into subsequent models. Stability of the model was assessed every time a variable was entered. The final step was to search for first-degree interaction. Criteria to include an interaction term were: (1) significant at $P<0.05$, (2) $1 \%$ of the sample had to exhibit the same combination factors, and (3) the combination should be clinically relevant. All patients were propensitymatched accordingly with the derived probability of death, on a $1 \mathrm{PM} \times 4$ non-PM number of patients basis (1:4 ratio). $52 / 65$ (80\%) PM patients (all on RRT before the device was implanted) and 208 non-PM matched subjects were suitable for comparison. A two-sided alpha level of 0.05 was considered statistically significant.

\section{Results}

From 2003 to 2008, 7129 new PMs were implanted in Uruguay (1188 per year); during this period, 1432 (20\%) PM patients died.

During the same time period, 2778 patients were on RRT, with an unadjusted annual mortality rate of $13.4 \%$. Chronic kidney diseases determinant of the loss of renal function were primary glomerulopathies $(12.6 \%)$, diabetic nephropathy $(21.5 \%)$, vascular nephropathy $(24.4 \%)$, obstructive nephropathy $(8.2 \%)$, tubule-interstitial nephropathy $(2.8 \%)$, other causes $(28.5 \%)$, and unknown cause $(2 \%)$. Mortality was secondary to cardiovascular diseases in 39.7\% (95\% CI 34-44), infectious diseases in $19.25 \%$ (15-23), discontinuation of treatment in $7.9(2-12)$, cancer in $8(6-9)$, and other causes in $26 \%(22-28)$.

110 of the $2778(3.9 \%)$ RRT patients were recipients of a PM, 41\% (45/110) before entering the RRT program, and 59\% (65/110) while on RRT.

The PM population on RRT corresponded to $1.9 \%$ of all PM implants in Uruguay in the observation period.

3.1. RRT Population. Mean followup was $93.6 \pm 63$ months. Patients in the PM group were older and predominantly male. (Figure 1) Comorbidities were extremely common. Table 1 shows baseline characteristics and comparison between groups; PM patients were older, with a significant male predominance; Kaplan-Meier survival time was significantly shorter. Within the PM group, there was a slightly higher prevalence of diabetes, and the functional status was significantly lower. A significantly higher incidence of stroke and neoplasic disease was observed. Those who received a PM while on RRT had the highest burden of comorbidities (Table 1).

3.2. Study Outcomes. Crude all-cause mortality was higher in the pacemaker group (60\% versus $54 \% P=0.2)$ with a different mean survival time $(29.7 \pm 2$ months versus $96.2 \pm$ 6 months, resp.; $P<0.05$ ). The mortality rate was 24.3 versus 14.9 per 100 patient-years, respectively, $P<0.05$ (Figure 2).

Variables associated with long-term mortality were: odds ratio (95\% CI); age 1.053 (1.043-1.062); age > 70 years; 1.5 (1.1$2.0)$ coronary heart disease; 1.8 (1.4-2.3) diabetes; 2.1 (1.5-2.8) COPD; 2.9 (1.9-4) Karnofsky modified score 1; 1.9 (1.5-2.3) Karnofsky modified score 2; 4.3 (3.09-6) Karnofsky modified score 3; 7.4 (3.3-16) peripheral vascular disease; 3 (2.1-4.3).

3.3. Propensity Matched Adjusted Groups. After propensity adjustment, no differences were observed in long-term mortality between both groups (Table 3 and Figure 3). 


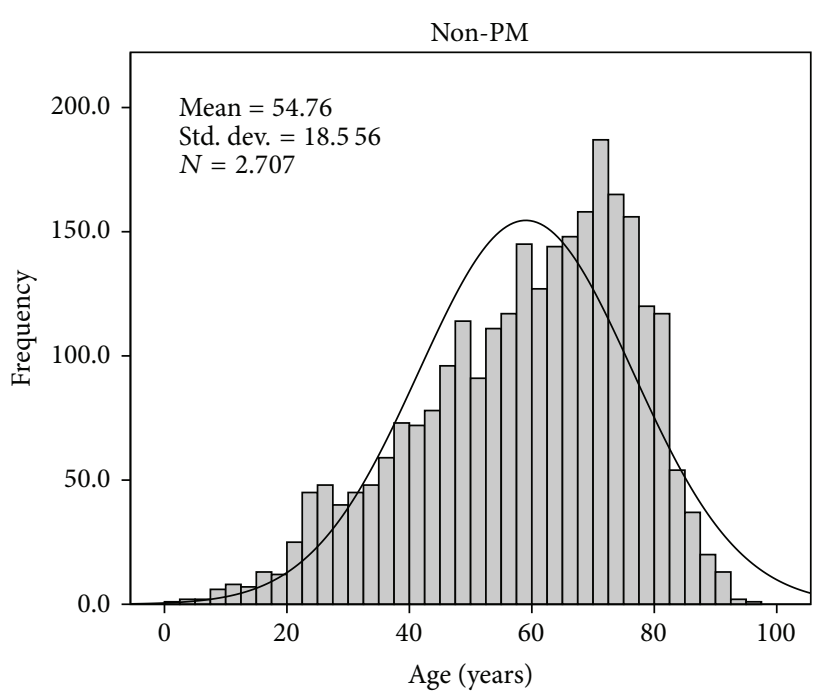

- Normal

(a)

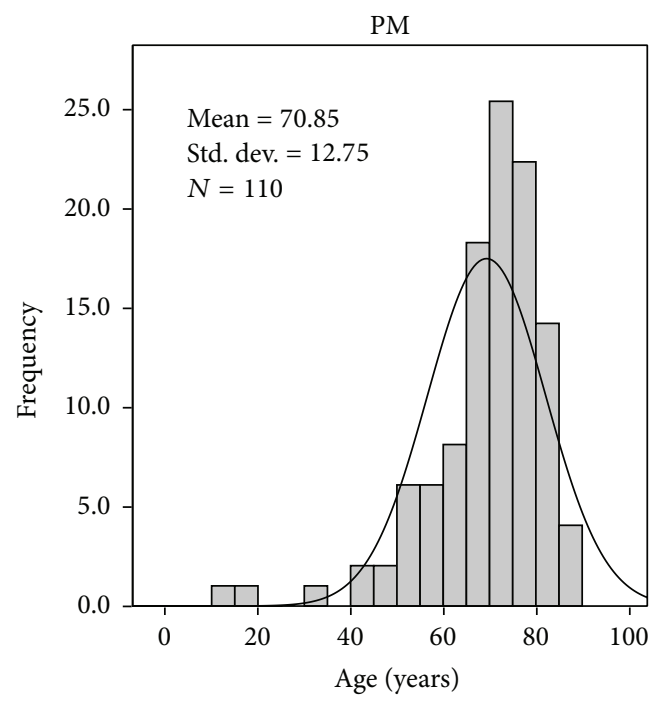

- Normal

(b)

FIGURE 1: Age histograms from both groups without pacemaker (a) and with pacemaker (b).

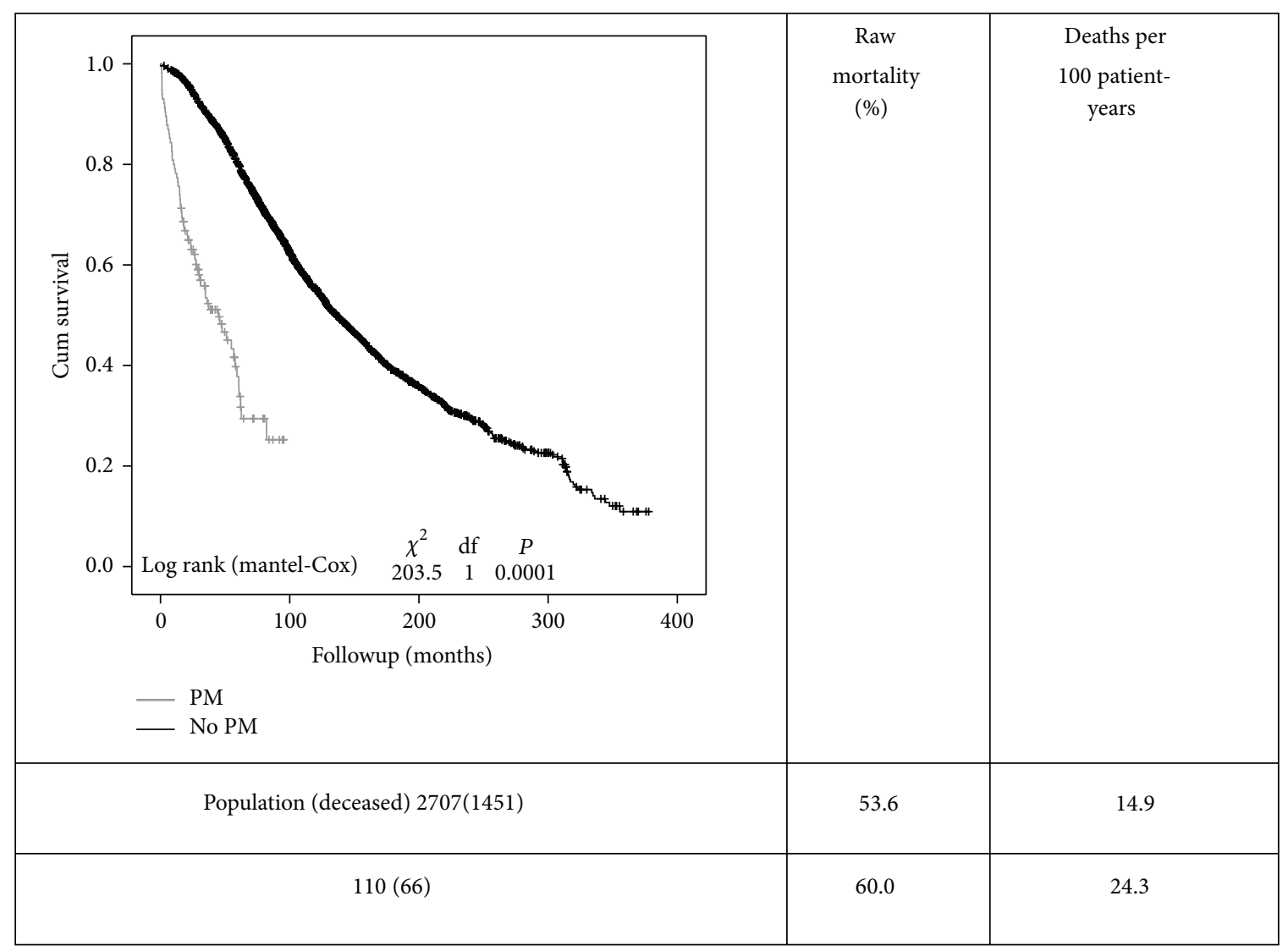

Figure 2: Kaplan-Meier survival curves comparing both groups (PM-pacemaker grey line and non-PM black line). Curves are quite different and show a high mortality in both groups, particularly in the PM group. Mortality (raw and adjusted) rates are shown on the right side of the figure. 
TAble 1: Patient demographics.

\begin{tabular}{|c|c|c|c|}
\hline & No PM & $\mathrm{PM}$ & PM after RRT (group A + C); see text \\
\hline$n(\%)$ & $2668(96)$ & $110(4)$ & $83(2.9)$ \\
\hline Age (years) & $59.0 \pm 1$ & $70.8 \pm 1^{*}$ & $69.5 \pm 14.5^{* *}$ \\
\hline Female gender $n(\%)$ & $1140(42)$ & $29(26)^{\mathrm{fT}}$ & $27(32.1)^{\mathrm{T}}$ \\
\hline Mean survival time (months) & $96.2 \pm 62$ & $29.7 \pm 22^{*}$ & $24 \pm 19^{* *}$ \\
\hline Previous time in RRT (years) & $5.2 \pm 4.6$ & NA & $4.8 \pm 4.6$ \\
\hline Arterial hypertension $n(\%)$ & $1272(47)$ & $61(55)$ & $50(60)$ \\
\hline $\mathrm{SBP}>140 \mathrm{mmHg}$ predialysis $n(\%)$ & $983(37)$ & $44(40)$ & $34(41)$ \\
\hline Antihypertensive treatment $n(\%)$ & $1042(38)$ & $53(48)$ & $45(54)$ \\
\hline $\mathrm{Hb} \geq 10 \mathrm{~g} \% n(\%)$ & $609(22)$ & $8 / 29(25)$ & $5 / 25(20)$ \\
\hline Coronary artery disease $n(\%)$ & $569(22)$ & $35(32)$ & $42(51.5)^{* *}$ \\
\hline Atrial fibrillation $n(\%)$ & $16^{\S}$ & $35(32)$ & $20(35)$ \\
\hline Valvular heart disease $n(\%)$ & NA & $13(11.8)$ & $8(9)$ \\
\hline Diabetes $n(\%)$ & $575(21)$ & $26(23)$ & $23(27.9)^{*}$ \\
\hline (a) Karnofsky $1 n$ (\%) & $1425(53)$ & $25(22)^{\mathrm{FF}}$ & $25(30.9)^{* *}$ \\
\hline (a) Karnofsky $2 n(\%)$ & $749(28)$ & $61(55)^{*}$ & $31(38.2)^{*}$ \\
\hline (a) Karnofsky $3 n$ (\%) & $392(15)$ & $24(22)$ & $19(23.5)^{*}$ \\
\hline (a) Karnofsky $4 n$ (\%) & $100(3.7)$ & $8(5.4)$ & $6(7.4)^{*}$ \\
\hline Previous stroke $n(\%)$ & $216(8.3)$ & $24(22)^{\mathrm{T}}$ & $29(35.3)^{* *}$ \\
\hline Smoker $n(\%)$ & $347(13)$ & $18(16)$ & $21(27.3)^{* *}$ \\
\hline Neoplastic disease $n(\%)$ & $202(7)$ & $19(17)^{\mathrm{FT}}$ & $22(27.5)^{\mathrm{fF}}$ \\
\hline Peripheral vascular disease $n(\%)$ & $417(15)$ & $19(17)$ & $22(27.5)^{* *}$ \\
\hline $\operatorname{COPD} n(\%)$ & $212(7.9)$ & $12(11)$ & $6(7.5)$ \\
\hline Mortality $n$ (mortality/rate 100 patient-years) & $1451(14.9)$ & $66(24.3)^{*}$ & $29(35.2)^{\mathrm{FF}}$ \\
\hline
\end{tabular}

All comparisons versus the non-PM group; ${ }^{*} P<0.05,{ }^{* *} P<0.01,{ }^{\mathrm{T}} \mathrm{P}<0.001$, and ${ }^{\mathrm{TF}} P<0.0001$.

${ }^{\mathfrak{S}}$ Data estimated from the international dialysis outcomes and practice patterns study (DOPPS).

NA: not available.

(a) 1: Able to carry on normal activity and to work; no special care needed. 2: Normal activity with effort; some signs or symptoms of disease; unable to work; able to live at home and care for most personal needs; varying amount of assistance needed. 3: Cares for self; unable to carry on normal activity or to do active work; requires occasional assistance but is able to care for most of his personal needs. 4: Unable to care for self; requires equivalent of institutional or hospital care; disease may be progressing rapidly.

Survival curves were not different in the RRT propensitymatched group. Coronary artery disease, age, and the Karnofsky modified score were the only independent variables associated with mortality in the propensity population, without differences between groups.

3.4. PM Population. The PM population could be divided into three groups: 64 (58\%) patients who received the PM while on RRT (group A), mean time of $68 \pm 56$ months on RRT before PM implantation. Group B: 27 (24\%) patients received the pacemaker before entering the RRT program (mean time $-26 \pm 21$ months) and Group C: 19 (17\%) patients received the device within 3 months before or after entering the RRT program ( $1 \pm 1.35$ months). Group A had a significantly higher mortality $(65 \%$ versus $52 \% P=0.05$, versus group B) and a shorter mean survival time (24 \pm 19 versus $36 \pm 25$ months), with a different age at implantation $(68 \pm 15$ versus $74 \pm 7$ years, $P<0.05)$ (Figure 4$)$. In these subgroups, the presence of atrial fibrillation was associated with a significantly higher mortality, group A versus group B plus group C, $21 \%$ versus $9 \%(P<0.006)$. VVI pacing was also associated with higher mortality rates, particularly in group A, 38\% $(P<0.003)$ versus $15 \%$ in groups B and $C$ together.
TABLE 2: Cause of death in the PM group.

\begin{tabular}{lc}
\hline & $N=66(\%)$ \\
\hline Cardiovascular & $17(20.9)$ \\
Cardiac arrest & $8(21.1)$ \\
End-stage dilated cardiomyopathy & $2(3)$ \\
Myocardial infarction & $3(4.5)$ \\
Stroke, including intracranial hemorrhage & $3(4.5)$ \\
Pulmonary edema due to exogenous fluid & $1(1.5)$ \\
Infection & $12(18.1)$ \\
Neoplasic disease & $1(1.5)$ \\
Unknown & $36(54.5)$ \\
\hline
\end{tabular}

Most deaths were cardiovascular (20.9\%), and approximately $10 \%$ were attributed to cardiac arrest or ventricular arrhythmias (Table 2). Deaths due to infections were common and observed in $18 \%$ of the patients, most of them not related to $\mathrm{PM}$ infections.

Survival within the PM group was longer in males than females $(32 \pm 23$ versus $23 \pm 16$ months, $P<0.05)$ despite an older but non-significant age at implantation (male $71.7 \pm 11$ 
TABLE 3: Characteristics of the propensity-matched adjusted groups.

\begin{tabular}{lccc}
\hline Variable & $\begin{array}{c}\text { No PM } \\
(n=208)\end{array}$ & $\begin{array}{c}\text { PM } \\
(n=52)^{\mathrm{a}}\end{array}$ & $P$ \\
\hline Predicted probability & $0.64 \pm 0.26$ & $0.64 \pm 0.25$ & NS \\
Age (years) & $65.2 \pm 13.4$ & $66.9 \pm 13.6$ & NS \\
Female gender (\%) & 41.8 & 42.6 & NS \\
Diabetes (\%) & 20.1 & 25 & NS \\
Previous time on RRT (years) & $5.06 \pm 4.4$ & $5.8 \pm 4.6$ & NS \\
Coronary heart disease (\%) & 46.2 & 49.8 & NS \\
Previous stroke (\%) & 16.3 & 23.5 & NS \\
Smoker (\%) & 11.5 & 17.3 & NS \\
Neoplastic disease (\%) & 7.7 & 15.4 & NS \\
Peripheral vascular disease (\%) & 21.5 & 28.8 & NS \\
COPD (\%) & 6.2 & 9.6 & NS \\
Functional status & & & \\
$\quad$ Karnofsky* 1 (\%) & 35.9 & 30.8 & NS \\
Karnofsky* 2 (\%) & 36.8 & 40.4 & NS \\
Karnofsky* 3 (\%) & 21.2 & 22 & NS \\
Karnofsky* 4 (\%) & 7.7 & 5.3 & NS \\
\hline As Table 1. & & &
\end{tabular}

*As in Table 1.

${ }^{a}$ All patients in this group had the PM implanted while on RRT.

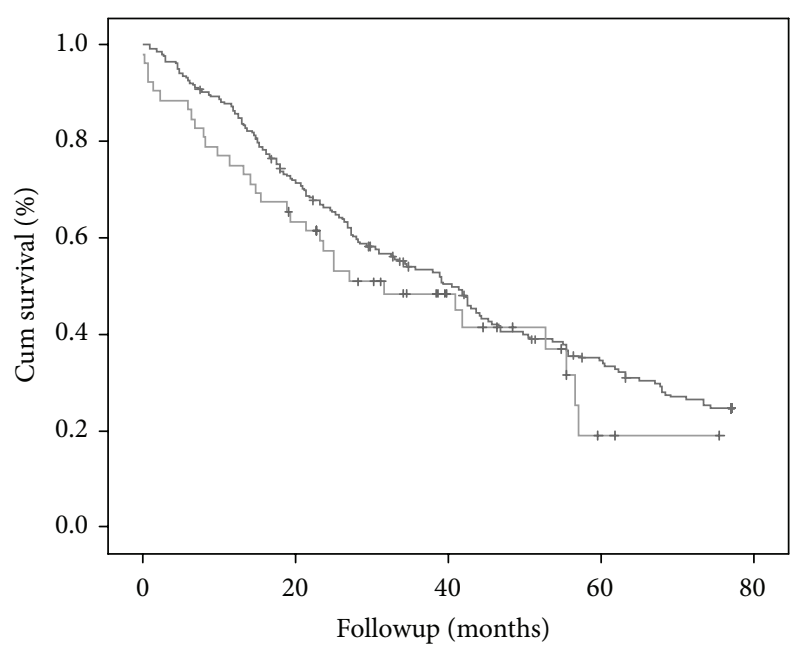

FIGURE 3: KM survival curve after propensity-matched adjustment. The darker grey line corresponds to the non-PM group and the lighter grey to $\mathrm{PM}$ group. There are no differences regarding survival between both groups $(P=\mathrm{NS})$.

years versus female $68 \pm 14$ years). The type of arrhythmia leading to the PM implant had no influence on survival. Patients with a VVI PM had a higher mortality compared to those with dual chamber PMs, with a significantly shorter mean survival time, $16 \pm 15$ months versus $47 \pm 23$ months, $P<0.05$ (Table 4 and Figure 4 ).
TABLE 4: Characteristics of the PM patients by survival outcome.

\begin{tabular}{lccc}
\hline & Alive & Dead & $P$ \\
\hline$n(\%)$ & $44(40)$ & $66(60)$ & \\
Age (mean \pm SD) & $69.7 \pm 11$ & $71.6 \pm 13$ & $0.3 \mathrm{NS}$ \\
Female gender $n(\%)$ & $11(25)$ & $18(27)$ & $0.8 \mathrm{NS}$ \\
Followup (months) (mean \pm SD) & $43 \pm 21$ & $21 \pm 18$ & 0.05 \\
Arterial hypertension $n(\%)$ & $29(66)$ & $32(48)$ & $0.08 \mathrm{NS}$ \\
Diabetes $n(\%)$ & $4(9)$ & $10(15)$ & $0.4 \mathrm{NS}$ \\
Atrial fibrillation $n(\%)$ & $17(38)$ & $18(27)$ & $0.2 \mathrm{NS}$ \\
Coronary artery disease $n(\%)$ & $6(13)$ & $13(19)$ & $0.4 \mathrm{NS}$ \\
Dilated cardiomyopathy $n(\%)$ & $2(4)$ & $7(10)$ & $0.3 \mathrm{NS}$ \\
LVEF \% (mean \pm SD) & $52.8 \pm 2$ & $50.8 \pm 1$ & $0.4 \mathrm{NS}$ \\
Valvular heart disease $n(\%)$ & $3(7)$ & $10(15)$ & $0.2 \mathrm{NS}$ \\
AV block $n$ (\%) & $23(52)$ & $42(63)$ & $0.24 \mathrm{NS}$ \\
Sick sinus syndrome $n(\%)$ & $18(41)$ & $23(34)$ & $0.5 \mathrm{NS}$ \\
VVI PM $n$ (\%) & $8(18)$ & $32(48)$ & 0.0013 \\
\hline
\end{tabular}

NS: not significant.

\section{Discussion}

Although PM implant is routinely performed in patients on RRT, there is no relevant data available in this group of patients. Patients on RRT have increased morbidity and mortality and are at increased risk of developing cardiac device-related infections. Interestingly, there is much more information of implantable cardioverter defibrillators (ICDs) and RRT [10, 24-40].

In our study, we found that crude mortality rates were higher in the PM group, averaging 24.3 deaths per 100 patient-years versus 14.9 deaths per 100 patient-years in the RRT population without PM. This finding is probably related to older age and associated comorbidities. However, after propensity adjustment, mortality was similar between groups.

Global mortality rates in patients on RRT and patients without PM were lower when compared to other countries, 18.6 deaths per 100 patient-years of unselected dialysis patients reported in 2008 in the US [5, 41].

Cardiovascular disease and particularly malignant arrhythmias remain the predominant cause of death in RRT patients; however, infections were a very frequent cause of death $[31,32]$.

Patients with ICDs have much higher mortality rates, with 45 deaths/100 patient-years of followup. Cardiovascular mortality accounts for two-thirds of all deaths, and more than half those deaths were due to arrhythmia despite the type of the implanted device $[28,41,42]$.

The high rate of deaths from arrhythmia after ICDdefibrillator or PM placement is consistent with studies showing higher defibrillation thresholds in dialysis patients than in individuals with preserved kidney function $[33,42]$. The uremic milieu, the major shifts in potassium and calcium concentrations during hemodialysis [41-44], may increase the likelihood of a sudden increase of capture thresholds, resulting in defibrillation-resistant arrhythmias, bradycardia, 


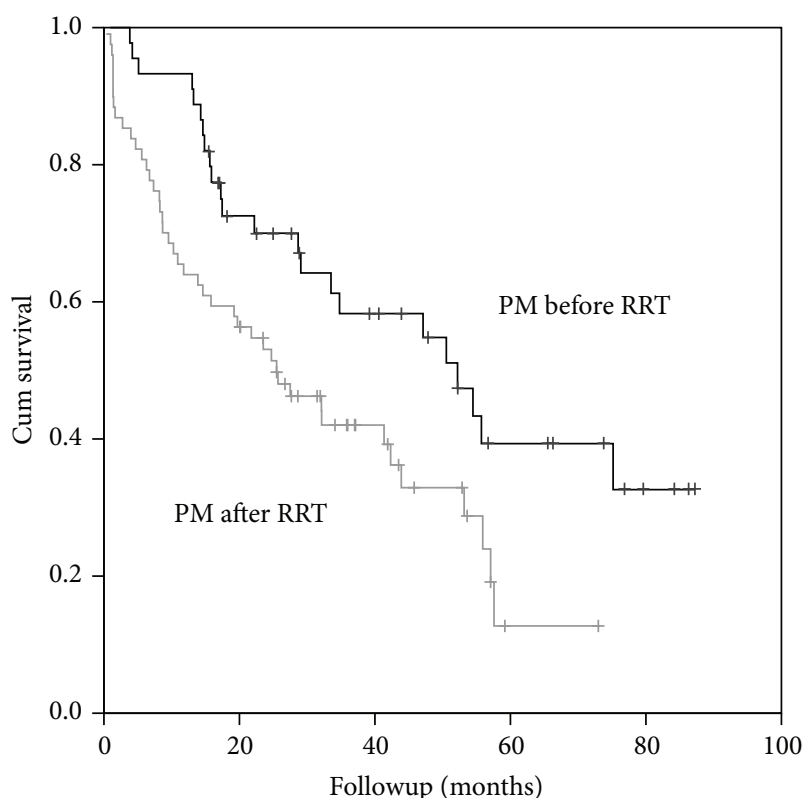

(a)

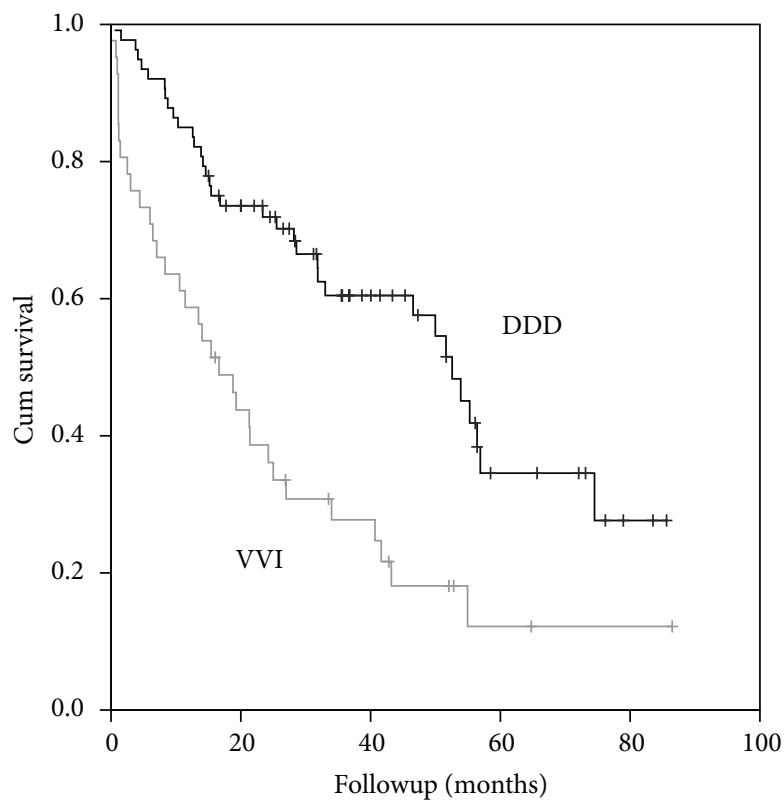

(b)

FIGURE 4: KM survival curves. (a) Mortality related to RRT; the grey lines correspond to the group of PM patients who received the device while on RRT and the black line corresponds to those who received the PM before entering the RRT program. Log rank (mantel-Cox); ChiSquare 6,2 df 1; $P=0.012$. (b) Mortality regarding PM mode, DDD versus VVI pacing. The grey line corresponds to the VVI PMs and the black line to the DDD devices. Log rank (mantel-Cox) Chi-Square 11,31 df $1 ; P=0.001$.

heart block, and primary pulseless electrical activity in RRT patients $[19,35]$.

Although not important in our population as a significant mortality cause, clinicians considering PM therapy should carefully evaluate a history of infections before device placement, an assessment that may be particularly important in patients with catheters or grafts. RRT patients are at great risk of infection due to the repeated exposure during intravenous access creating a permanent potential menace of infection long after PM implantation. Reduction of device-related infections continues to be a clinical challenge. Irrigation of the pocket with antibiotics, antibacterial meshs coated with antibiotics, and/or use of prophylactic antibiotics had been shown to reduce infection rates [45].

Cost-effectiveness analyses should be implemented to assess mortality risk factors in order to clearly define the optimal PM indications in the RRT population, particularly the need for cardiac resynchronization therapy with or without an ICD. Those with depressed left ventricular function and atrial fibrillation have a significantly higher mortality rate.

In the near future, this population will definitively benefit form leadless PM to overcome infections.

4.1. Study Limitations. There are several limitations to our study. It was a retrospective observational study and the information contains administrative data rather than clinical records, but the data was prospectively recorded using a standardized data collection instrument, allowing for the best quality of data acquisition in these types of observational studies. The number of patients suitable for the propensity analysis in the PM group was quite small. However, $80 \%$ of patients that received a PM while on RRT were included in the propensity risk-adjusted analysis.

Cardiovascular outcomes were not adjudicated independently, and important conditions, device-related complications, potassium level, and medication, were unavailable for analysis.

\section{Conclusions}

Patients on RRT with an implanted PM had significantly higher mortality rates; however, this observation is related to the burden of comorbidity. The presence of a PM is not an independent risk factor for mortality.

Patients on RRT that receive a PM have a worse prognosis than those that had the PM implanted before entering RRT.

Single chamber pacemakers had a significantly higher mortality and should be avoided if possible.

\section{Conflict of Interests}

The authors declare that there is no conflict of interests regarding the publication of this paper.

\section{Acknowledgment}

The authors are thankful to the National Resource Fund of Uruguay. 


\section{References}

[1] S. S. Raza, J.-M. Li, R. John et al., "Long-term mortality and pacing outcomes of patients with permanent pacemaker implantation after cardiac surgery," Pacing and Clinical Electrophysiology, vol. 34, no. 3, pp. 331-338, 2011.

[2] M. Brunner, M. Olschewski, A. Geibeli, C. Bode, and M. Zehender, "Long-term survival after pacemaker implantation: prognostic importance of gender and baseline patient characteristics," European Heart Journal, vol. 25, no. 1, pp. 88-95, 2004.

[3] B. Schmidt, M. Brunner, M. Olschewski et al., "Pacemaker therapy in very elderly patients: long-term survival and prognostic parameters," American Heart Journal, vol. 146, no. 5, pp. 908913, 2003

[4] J. R. Pyatt, J. D. Somauroo, M. Jackson et al., "Long-term survival after permanent pacemaker implantation: analysis of predictors for increased mortality," Europace, vol. 4, no. 2, pp. 113-119, 2002.

[5] US Renal Data System, USRDS, 2008 Annual Data Report: Atlas of End-Stage Renal Disease in the United States, National Institutes of Health, National Institute of Diabetes and Digestive and Kidney Diseases, Bethesda, Md, USA, 2008.

[6] B. Kestenbaum, K. D. Rudser, M. G. Shlipak et al., "Kidney function, electrocardiographic findings, and cardiovascular events among older adults," Clinical Journal of the American Society of Nephrology, vol. 2, no. 3, pp. 501-508, 2007.

[7] Y. Ishikawa, "Arrhythmia and conduction abnormalities in hemodialysis patients," Nippon Rinsho, vol. 62, pp. 237-245, 2004.

[8] C. A. Herzog, "Can we prevent sudden cardiac death in dialysis patients?" Clinical Journal of the American Society of Nephrology, vol. 2, no. 3, pp. 410-412, 2007.

[9] A. A. Alsheikh-Ali, T. A. Trikalinos, R. Ruthazer et al., "Risk of arrhythmic and nonarrhythmic death in patients with heart failure and chronic kidney disease," American Heart Journal, vol. 161, no. 1, pp. 204.el-209.el, 2011.

[10] C. Arsenescu, G. I. Georgescu, A. Covic, and L. Briotǎ, "Permanent cardiac pacing for chronic symptomatic atrioventricular block in uremic hemodialysed patients. A prospective study," Revista Medico-Chirurgicala a Societatii de Medici si Naturalisti din Lasi, vol. 106, no. 1, pp. 112-121, 2002.

[11] H. Kohno, M. Hisahara, M. Umesue et al., "Permanent cardiac pacing in patients on chronic dialysis," Nihon Kyobu Geka Gakkai Zasshi, vol. 39, no. 7, pp. 992-995, 1991.

[12] R. B. Leman, J. M. Kratz, and P. C. Gazes, "Permanent cardiac pacing in patients on chronic renal dialysis," American Heart Journal, vol. 110, no. 6, pp. 1242-1244, 1985.

[13] A. E. Epstein, J. P. DiMarco, K. A. Ellenbogen et al., "ACC/AHA/HRS 2008 Guidelines for Device-Based Therapy of Cardiac Rhythm Abnormalities. A Report of the American College of Cardiology/American Heart Association Task Force on Practice Guidelines (Writing Committee to Revise the ACC/AHA/NASPE 2002 Guideline Update for Implantation of Cardiac Pacemakers and Antiarrhythmia Devices)," Journal of the American College of Cardiology, vol. 51, no. 21, pp. el-e62, 2008.

[14] P. E. Vardas, A. Auricchio, J.-J. Blanc et al., "Guidelines for cardiac pacing and cardiac resynchronization therapy. The Task Force for Cardiac Pacing and Cardiac Resynchronization Therapy of the European Society of Cardiology. Developed in collaboration with the European Heart Rhythm Association," Europace, vol. 9, no. 10, pp. 959-998, 2007.

[15] D. A. Drew, K. B. Meyer, and D. E. Weiner, "Transvenous cardiac device wires and vascular access in hemodialysis patients," American Journal of Kidney Diseases, vol. 58, no. 3, pp. 494-496, 2011.

[16] A. Asif, L. H. Salman, G. G. Lopera, and R. G. Carrillo, "The dilemma of transvenous cardiac rhythm devices in hemodialysis patients: time to consider the epicardial approach," Kidney International, vol. 79, no. 12, pp. 1267-1269, 2011.

[17] H. Bloom, B. Heeke, A. Leon et al., "Renal insufficiency and the risk of infection from pacemaker or defibrillator surgery," Pacing and Clinical Electrophysiology, vol. 29, no. 2, pp. 142-145, 2006.

[18] C.-F. Chang, B. I.-T. Kuo, T.-L. Chen, W.-C. Yang, S.-D. Lee, and C.-C. Lin, "Infective endocarditis in maintenance hemodialysis patients: fifteen years' experience in one medical center," Journal of Nephrology, vol. 17, no. 2, pp. 228-235, 2004.

[19] K. Mischke, T. Schimpf, C. Knackstedt, and P. Schauerte, "Pacemaker with 2:1 hyperkalemic ventricular exit block," International Journal of Cardiology, vol. 116, no. 1, pp. 117-119, 2007.

[20] T. H. Teruya, A. M. Abou-Zamzam Jr., W. Limm, L. Wong, and L. Wong, "Symptomatic subclavian vein stenosis and occlusion in hemodialysis patients with transvenous pacemakers," Annals of Vascular Surgery, vol. 17, no. 5, pp. 526-529, 2003.

[21] F. Cavatorta, S. Campisi, and A. Zollo, "Subclavian vein stenosis: a potentially serious complication in chronic hemodialysis patients with permanent cardiac pacemakers," International Journal of Artificial Organs, vol. 20, no. 6, pp. 316-318, 1997.

[22] N. Mazzuchi, E. Schwedt, L. Solá, C. González, and A. Ferreiro, "Risk factors and prevention of end stage renal disease in Uruguay," Renal Failure, vol. 28, no. 8, pp. 617-625, 2006.

[23] N. Mazzuchi, E. Schwedt, C. Gonzalez et al., "Uruguayan registry committee of dialysis: evaluation of the dialysis program for the treatment of chronic kidney disease in Uruguay," Archives of Internal Medicine Uruguay, vol. 22, pp. 1-71, 2000.

[24] E. S. Williams, S. H. Shah, J. P. Piccini et al., "Predictors of mortality in patients with chronic kidney disease and an implantable defibrillator: an EPGEN substudy," Europace, vol. 13, no. 12, pp. 1717-1722, 2011.

[25] C. Tompkins, R. McLean, A. Cheng et al., "End-stage renal disease predicts complications in pacemaker and ICD implants," Journal of Cardiovascular Electrophysiology, vol. 22, no. 10, pp. 1099-1104, 2011

[26] I. Ahmed, E. Gertner, W. B. Nelson, C. M. House, and D. W. $\mathrm{X}$. Zhu, "Chronic kidney disease is an independent predictor of pocket hematoma after pacemaker and defibrillator implantation," Journal of Interventional Cardiac Electrophysiology, vol. 29, no. 3, pp. 203-207, 2010.

[27] C. S. Hager, S. Jain, J. Blackwell, B. Culp, J. Song, and C. D. Chiles, "Effect of renal function on survival after implantable cardioverter defibrillator placement," American Journal of Cardiology, vol. 106, no. 9, pp. 1297-1300, 2010.

[28] D. M. Charytan, A. R. Patrick, J. Liu et al., "Trends in the use and outcomes of implantable cardioverter-defibrillators in patients undergoing dialysis in the united states," American Journal of Kidney Diseases, vol. 58, no. 3, pp. 409-417, 2011.

[29] S. Hiremath, S. R. Punnam, S. S. Brar et al., "Implantable defibrillators improve survival in end-stage renal disease: results from a multi-center registry," American Journal of Nephrology, vol. 32, no. 4, pp. 305-310, 2010. 
[30] R. Sakhuja, M. Keebler, T.-S. Lai, C. McLaughlin Gavin, R. Thakur, and D. L. Bhatt, "Meta-analysis of mortality in dialysis patients with an implantable cardioverter defibrillator," American Journal of Cardiology, vol. 103, no. 5, pp. 735-741, 2009.

[31] J. Robin, K. Weinberg, J. Tiongson et al., "Renal dialysis as a risk factor for appropriate therapies and mortality in implantable cardioverter-defibrillator recipients," Heart Rhythm, vol. 3, no. 10, pp. 1196-1201, 2006.

[32] D. S. Lee, J. V. Tu, P. C. Austin et al., "Effect of cardiac and noncardiac conditions on survival after defibrillator implantation," Journal of the American College of Cardiology, vol. 49, no. 25, pp. 2408-2415, 2007.

[33] A. Wase, A. Basit, R. Nazir et al., "Impact of chronic kidney disease upon survival among implantable cardioverterdefibrillator recipients," Journal of Interventional Cardiac Electrophysiology, vol. 11, no. 3, pp. 199-204, 2004.

[34] J. I. Koontz, D. Haithcock, V. Cumbea et al., "Rationale and design of the Duke Electrophysiology Genetic and Genomic Studies (EPGEN) biorepository," American Heart Journal, vol. 158, no. 5, pp. 719-725, 2009.

[35] A. Dasgupta, J. Montalvo, S. Medendorp et al., "Increased complication rates of cardiac rhythm management devices in ESRD patients," American Journal of Kidney Diseases, vol. 49, no. 5, pp. 656-663, 2007.

[36] T. Kusaba, S. Tanda, H. Kameyama et al., "Efficacy of biventricular pacing for dialysis-related hypotension due to idiopathic dilated cardiomyopathy," Clinical and Experimental Nephrology, vol. 9, no. 3, pp. 255-259, 2005.

[37] F. G. Hage, W. AlJaroudi, H. Aggarwal et al., "Outcomes of patients with chronic kidney disease and implantable cardiac defibrillator: primary versus secondary prevention," International Journal of Cardiology, vol. 165, no. 1, pp. 113-116, 2013.

[38] N. Lam, P. Leong-Sit, and A. X. Garg, "The role of implantable cardioverter-defibrillators in long-term dialysis patients," American Journal of Kidney Diseases, vol. 58, no. 3, pp. 338-339, 2011.

[39] L. A. Cannizzaro, J. P. Piccini, U. D. Patel, and A. F. Hernandez, "Device therapy in heart failure patients with chronic kidney disease," Journal of the American College of Cardiology, vol. 58, no. 9, pp. 889-896, 2011.

[40] O. A. Ajijola, E. A. MacKlin, S. A. Moore et al., "Inpatient vs. elective outpatient cardiac resynchronization therapy device implantation and long-term clinical outcome," Europace, vol. 12, no. 12, pp. 1745-1749, 2010.

[41] J.-W. Chae, C. S. Song, H. Kim, K.-B. Lee, B.-S. Seo, and D.-I. Kim, "Prediction of mortality in patients undergoing maintenance hemodialysis by Charlson Comorbidity Index using ICD-10 database," Nephron: Clinical Practice, vol. 117, no. 4, pp. c379-c384, 2011.

[42] US Renal Data System, USRDS 2010 Annual Data Report: Atlas of Chronic Kidney Disease and End-Stage Renal Disease in the United States, National Institutes of Health, National Institute of Diabetes and Digestive and Kidney Diseases, Bethesda, Md, USA, 2010.

[43] A. J. Bleyer, G. B. Russell, and S. G. Satko, "Sudden and cardiac death rates in hemodialysis patients," Kidney International, vol. 55, no. 4, pp. 1553-1559, 1999.

[44] A. J. Bleyer, J. Hartman, P. C. Brannon, A. Reeves-Daniel, S. G. Satko, and G. Russell, "Characteristics of sudden death in hemodialysis patients," Kidney International, vol. 69, no. 12, pp. 2268-2273, 2006.
[45] J. C. de Oliveira, M. Martinelli, S. A. Nishioka et al., "Efficacy of antibiotic prophylaxis before the implantation of pacemakers and cardioverter-defibrillators: Results of a large, prospective, randomized, double-blinded, placebo-controlled trial," Circulation: Arrhythmia and Electrophysiology, vol. 2, pp. 29-34, 2009. 


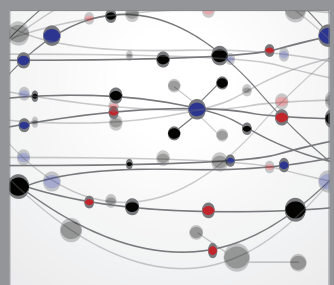

The Scientific World Journal
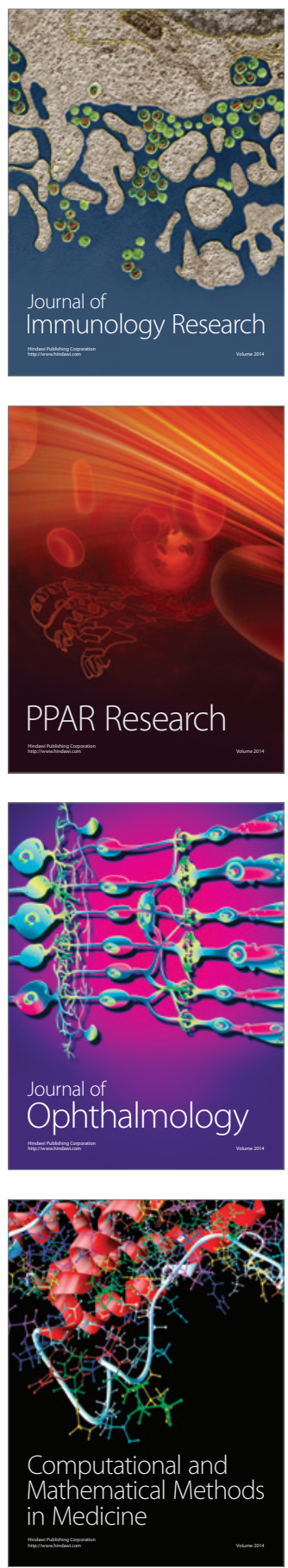

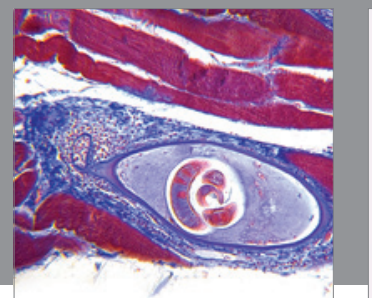

Gastroenterology

Research and Practice
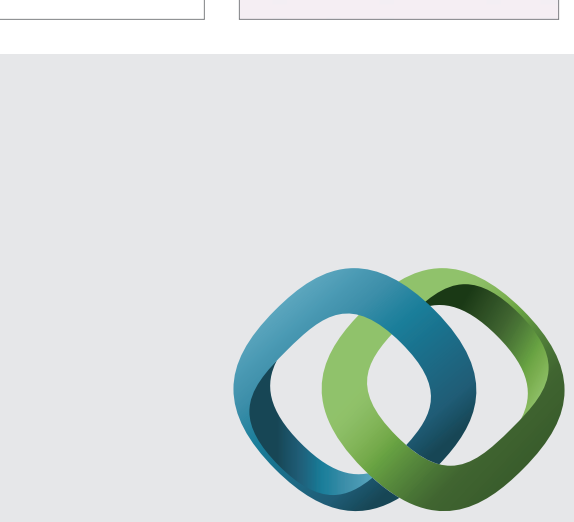

\section{Hindawi}

Submit your manuscripts at

http://www.hindawi.com
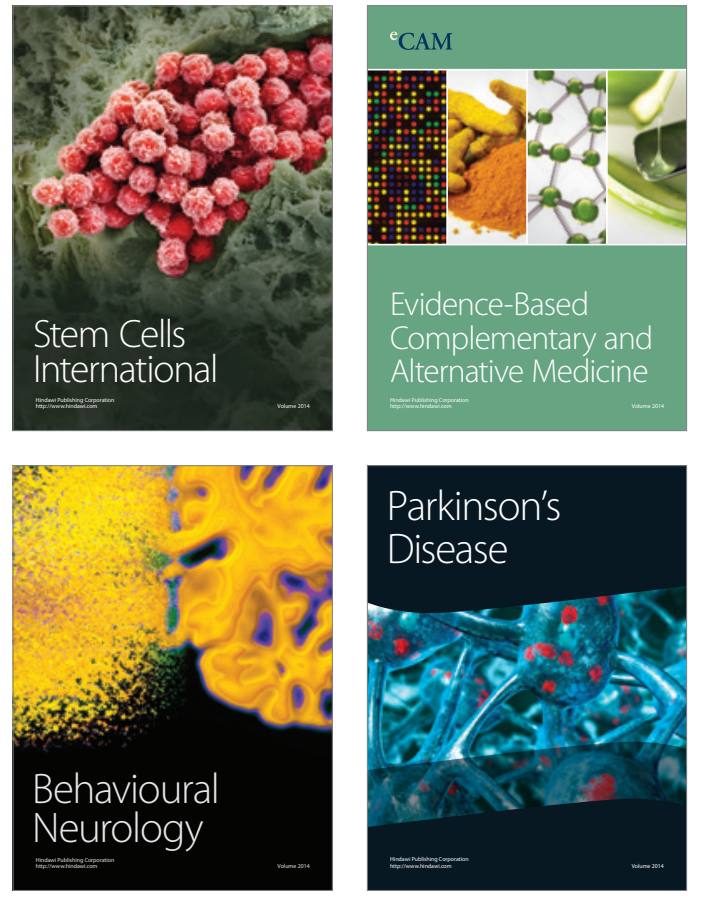
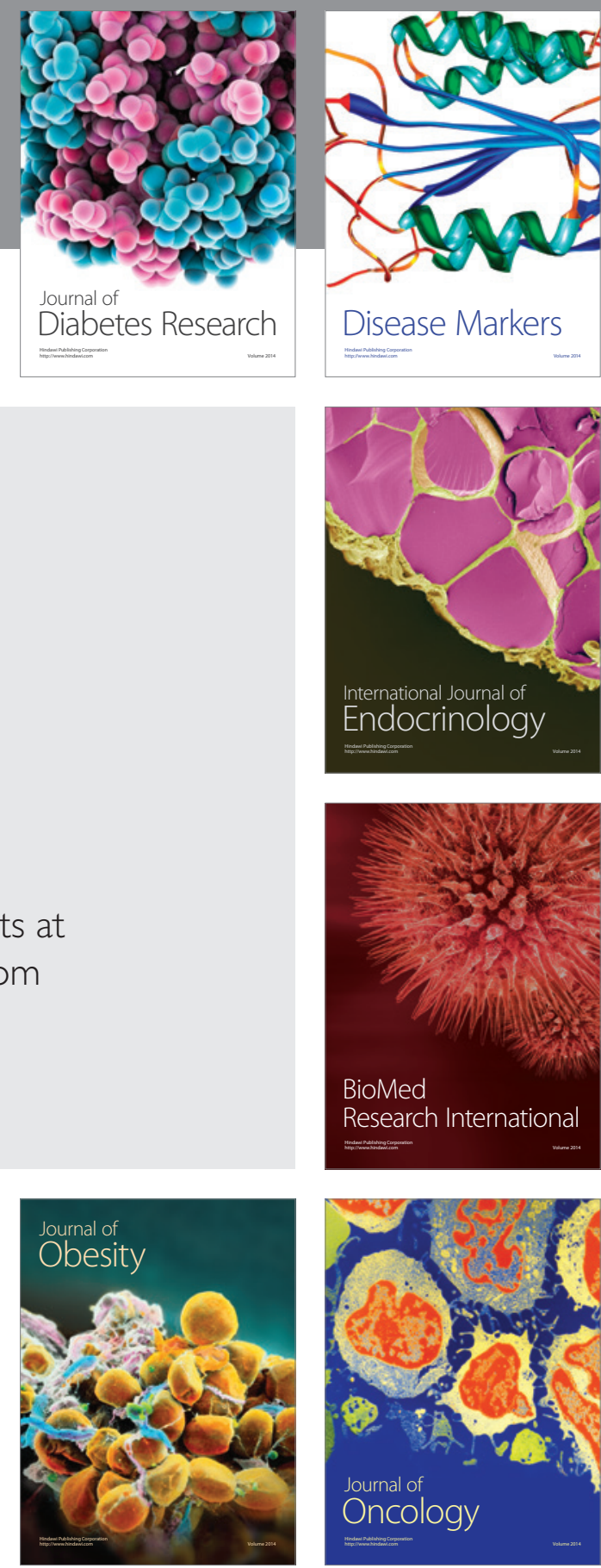

Disease Markers
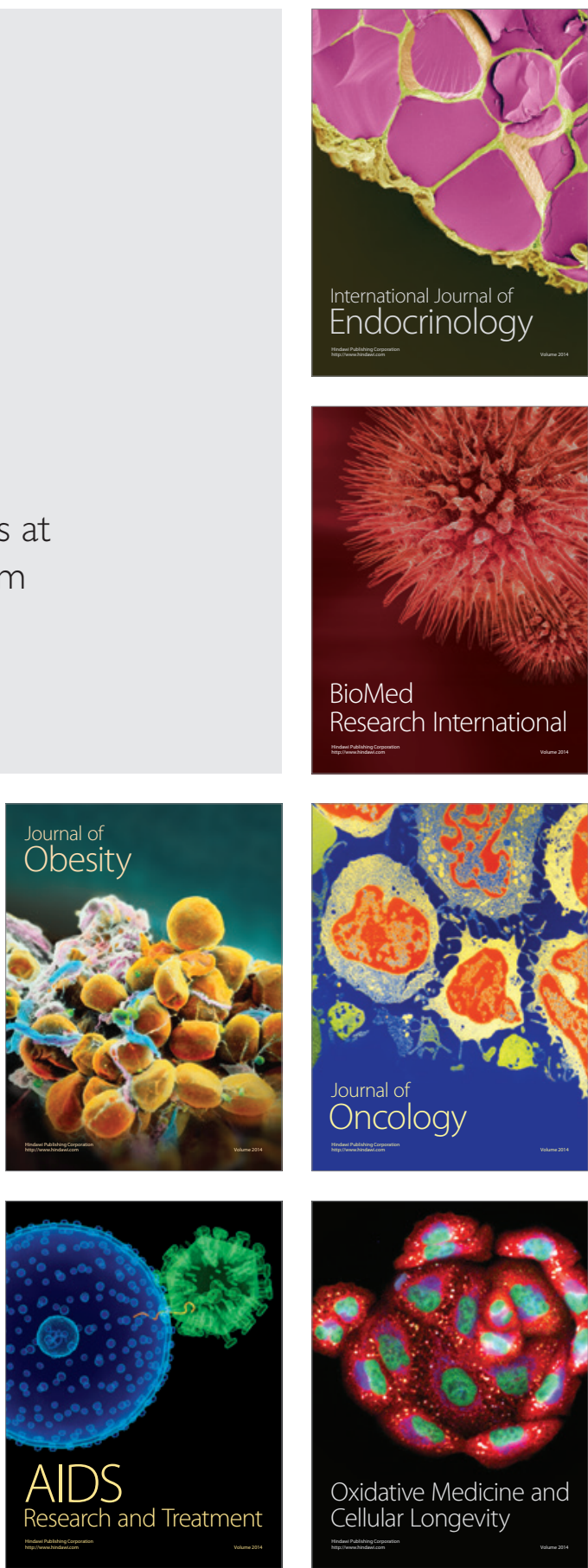